\title{
Backyard Chicken Farming Role in Supplementing Household Economy of District Quetta, Pakistan
}

\author{
Kamran Baseer Achakzai ${ }^{1, a, *}$, Muhammad Abbas Shah, ${ }^{1, b}$, Ramla Achakzai $^{2, c}$, Ghulam Hussain Kakar ${ }^{1, d}$ \\ ${ }^{1}$ Livestock \& Dairy Development Department, Balochistan, Pakistan \\ ${ }^{2}$ Centre for Advanced Studies in Vaccinology \& Biotechnology (CASVAB), University of Balochistan, Pakistan
}

*Corresponding author

\begin{tabular}{|c|c|}
\hline A R T I C LE I N F O & A B S T R A C T \\
\hline $\begin{array}{l}\text { Keywords: } \\
\text { Backyard poultry } \\
\text { Farming } \\
\text { Household economy } \\
\text { Quetta } \\
\text { Balochistan }\end{array}$ & $\begin{array}{l}\text { Backyard chicken farming is as an effective tool for poverty reduction in rural areas, by providing } \\
\text { living to resource poor communities; it is an important source of extra cash income other than eggs } \\
\text { and meat for family consumption. The present study was carried out to assess the role of backyard } \\
\text { poultry farming in supplementing household economy of rural farmers dwelling in district Quetta, } \\
\text { Pakistan. Information from ninety-nine randomly selected female backyard poultry farmers were } \\
\text { gathered during November } 2016 \text { to March } 2017 \text {. Owing to previous government and non- } \\
\text { government interventions backyard poultry keeping was found as an established practice. Women } \\
\text { were found the main custodian of backyard poultry birds and consequently were the main beneficiary } \\
\text { of the activity. Poultry birds of Fayoumi and Golden / Rhode Island Red (RIR) breeds were the main } \\
\text { types. Majority of the farmers reared these birds under scavenging conditions in combination with } \\
\text { feeding on household left over dry bread ( } 52 \% \text { ); most of the respondents (62\%) were taking care of } \\
\text { the birds by themselves which resulted in overall low production cost. Income included the earning } \\
\text { received from sale of birds, eggs and the home consumption of poultry meat and eggs. Net income } \\
\text { per annum per household was estimated as Pakistani Rupee (PKR) 79290/- (US\$ 566). The estimated } \\
\text { Rank Based Quotients (R.B.Q) based on farmers perception disclosed backyard poultry keeping as } \\
\text { an important domestic source of meat and eggs with almost no or very little capital investment, } \\
\text { ranked (I, } 80 \% \text { ) followed by a substantial source of supplementary income and was ranked (II, } 79 \% \text { ). } \\
\text { Amongst the problems, disease outbreaks were the most prevailing problem (I, 90\%) followed by } \\
\text { unavailability of vaccines (II, 85\%). The backyard poultry farming generated subsistence income } \\
\text { and provided high quality valuable food that improved household nutrition. }\end{array}$ \\
\hline
\end{tabular}

\section{Introduction}

Balochistan is the largest but poorest province of Pakistan having over two-third $(71 \%)$ of the population living in a state of multi-dimensional poverty. Provincial capital Quetta has around 50\% incidence of poverty (BRSP, 2018). District Quetta has an area of 2653 square kilo meter (Sq. km) with population density of $286.4 / \mathrm{sq} . \mathrm{km}$ (Pervaiz, 2011). Like other parts of province livestock and poultry has an important role in providing income and food to the rural dwellers of Quetta district while backyard poultry production has a significant role in their rural household economy. It provides eggs and meat for family consumption and to some extent cash income as well, which enhances rural livelihoods by stimulating economic growth of resource poor household in rural areas. Role of backyard poultry farming in sustaining and enhancing poor peoples' livelihoods in developing countries is well recognized among the development community (Ahuja et al., 2008; Pradeepta et al., 2015). It has been recognized that organizing rural communities around their comparative advantage is essential to address the issue of low population density and enabling people to ensure local resource mobilization. Rural poultry rearing has a wellrecognized role in improving food and nutrition security of the poorest households, reducing the livelihood weaknesses, insecurity and boosting gender equity (Dolberg, 2004; Ahuja, 2004; Alabi et al., 2006; Sonaiya, 2007; Ahuja and Sen, 2007; Smucker and Wisner, 2008). Backyard poultry farming can efficiently convert the waste materials such as insects, fallen grains, kitchen and vegetable wastes, green grass etc. into eggs and meat for human consumption and is one of the most apparent benefit. (Obi et al., 2008; Pathak and Nath, 2013; Islam et al., 2014; Patel et al., 2014; Awasthi et al., 2015). 
The potential to alleviate poverty offered by backyard poultry farming has already been realized by rural people, government and non-government organizations, working in different areas of province and are playing their role in the economic uplift of rural household. These organizations are involved in providing Fayoumi and Rhode Island Red (RIR) birds in the area at subsidized rates, along with capacity building and other associated facilities like provision of medicines and equipment etc. in order to stimulate the economic growth of poor rural household.

Present study was planned to investigate the economic status of backyard poultry in district Quetta of Pakistan. Relevant findings from this study might be useful for devising strategies for optimum productivity from the backyard chicken production in the area. It is realized that involvement of farmers in problem identification and prioritization is important (Uzunlu et al., 1999), so as to design relevant programs to cater the needs of farmers, while estimating technological needs and solutions in formulating need based extension programs for backyard poultry development at rural level. The survey questionnaire was designed to investigate the economics of reared birds and simultaneously the farmers were asked to rank the tangible benefits of the practice and classify different problems based on importance, urgency and magnitude. To categorize the perception of rural household about the importance of backyard poultry rearing and to envisage the problems as envisioned by them; for Rank based Quotients (RBQ) were estimated to have a meaningful interpretation in this regard.

\section{Materials and Methods}

\section{Study Area}

The study was carried out in Quetta District of Pakistan. It is located between $30^{\circ} 10^{\prime} 59.7720^{\prime \prime} \mathrm{N}$ and $66^{\circ} 59^{\prime}$ 47.2272" E absolute locations. Its altitude from sea level is 1682 meters above and has a semi-arid climate with an average annual precipitation of $261 \mathrm{~mm}$. (WORLDATLAS, 2019).

\section{Sampling Procedure}

District is administratively divided into three sub units (tehsils) namely Quetta, Kuchhlak and Panjpai; considering the data need and area accessibility, out of thirty-six union councils, nine (Chasma Achozai, Rahim Gul, Nohsar, Pashtoonabad, Sabzal, Saraghurgai, Kechi Baig, Khuchlak and Panjpai) were selected purposely on the basis of proportional sampling technique. While ninety-nine families already engaged and accustomed to backyard poultry rearing were randomly selected from these union councils.

\section{Data Collection and Analysis}

Before going to the final data collection, a pilot study was carried out and accordingly a structured interview schedule was constructed through participatory method. Primary data was personally collected from the respondents through structured questionnaire, that was based on both closed and open ended questions during November 2016 to March 2017. The data were collected through face to face interview and by direct observation method in farmer's homes or fields. Data were analyzed by using MS excel software to infer the results. Rank Based Quotient (RBQ) was estimated using the formula developed by Sabarathnam and Vennila, (1996):

$$
\mathrm{RBQ}=\frac{\sum_{\mathrm{i}=1}\left(\mathrm{~F}_{\mathrm{i}}\right)(\mathrm{n}+1-\mathrm{i})}{\mathrm{Nn}} \times 100
$$

$\mathrm{F}_{\mathrm{i}} \quad=$ Frequency of farmers for the it $\mathrm{h}$ rank of the technological need

$\mathrm{N} \quad=$ Number of respondents

$\mathrm{n} \quad=$ Number of problems identified

$\Sigma=$ It directs to sum the multiplication factor in the formula

\section{Results and Discussion}

\section{Performance of Backyard Poultry}

The studied area had uneven agro-ecological conditions consequently backyard poultry keeping practices were variable. Majority of the farmers reared their birds under scavenging feeding conditions in combination with household leftover dry bread (52\%), followed by household leftover dry bread in combination with available cereals (23\%). Majority (62\%) of the respondents take care of the birds by themselves resulting in overall low production cost. Including the home consumption of poultry meat and eggs, net income per annum per household was estimated as Pakistani Rupee (PKR) 79290/- (US\$ 566). Households used this increased cash income to meet various day to day expenditures like paying for educational expenditures, medical emergencies, overcoming food shortages and other little life indulgence. This was possible only because of backyard poultry farming provided marketable surplus, to some extent, to make it worthwhile for individuals to meet essential family needs. Study findings are in agreement with those reported by Ahuja et al. (2008), Debnath et al. (2011), Meena et al. (2012), Larbi et al. (2013), Dhaka et al. (2017).

Table 1. Performance of backyard poultry farming in District Quetta, Pakistan

\begin{tabular}{c|lr}
\hline SN & \multicolumn{1}{|c}{ Particulars } & P \\
\hline 1. & Average flock size (Nos.) & 27 \\
2. & Birds sold/Self consumed (Nos.) & 56 \\
3. & Average market price per bird (PKR) & 450 \\
4. & Total Revenue from birds (PKR) & 25,200 \\
5. & Eggs sold/Self consumed (Nos.) & 4,190 \\
6. & Average market price per egg (PKR) & 15 \\
7. & Total Revenue from eggs (PKR) & 62,850 \\
8. & Feed cost (PKR) & 7,300 \\
9. & Other cost (PKR) & 1,460 \\
10. & Total cost (PKR) & 8,760 \\
11. & Annual revenue per household (PKR) & 79,290 \\
\hline
\end{tabular}

PKR: Pakistani Rupee, P: Performance

\section{Perceived Benefits}

During the study, perception of respondents about benefits of backyard poultry farming were envisaged from the respondents. The beneficiaries came to regard that backyard poultry farming was an important livelihood enhancement that provided many benefits for all. While the benefits of backyard poultry farming were widely known, each 
respondent had their own perception and priorities (Table 2). These findings revealed that respondents perceived backyard poultry farming as an important domestic source of meat and eggs with almost no or very little capital investment by having the highest rank (I) in the observed benefits. Others described the practice of backyard poultry farming as a substantial source of supplementary income and this was ranked (II) on the basis of estimated R.B.Q (79\%). Other benefits included the role of backyard poultry keeping in alleviation of impacts of malnutrition (III) and its role in offering an employment opportunity (IV) in rural areas with respective R.B.Q of 60 and 49 in hierarchy, respectively. These perceived benefits were also in line with those concluded by Patel et al., (2014); Awasthi et al., (2015); Rath et al., (2015);Dhaka et al., (2017).

\section{Observed Problems}

The perceived problems and their rankings are shown in Table 3; the study revealed that disease outbreaks were the most prevailing problem (I) with R.B.Q. of 90, being faced by backyard poultry farmers; almost all of the farmers pointed out the Newcastle disease as most dreadful. The other perceived problems included were unavailability of vaccines, feed availability and quality of available feed and marketing of eggs with relative hierarchical setup of II, III, IV and V, respectively. Problems faced to study respondents are in-lined with those observed by Sarwar et al., (2015).

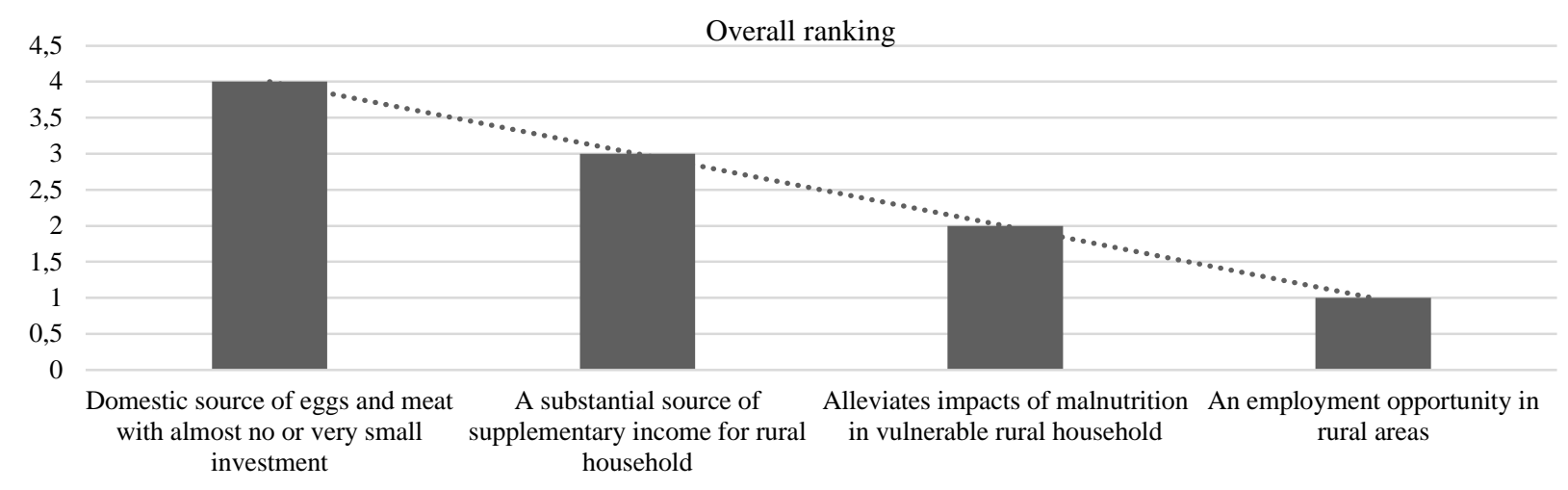

Figure 1a. Observed benefits of backyard poultry farming according to their ranking in District Quetta

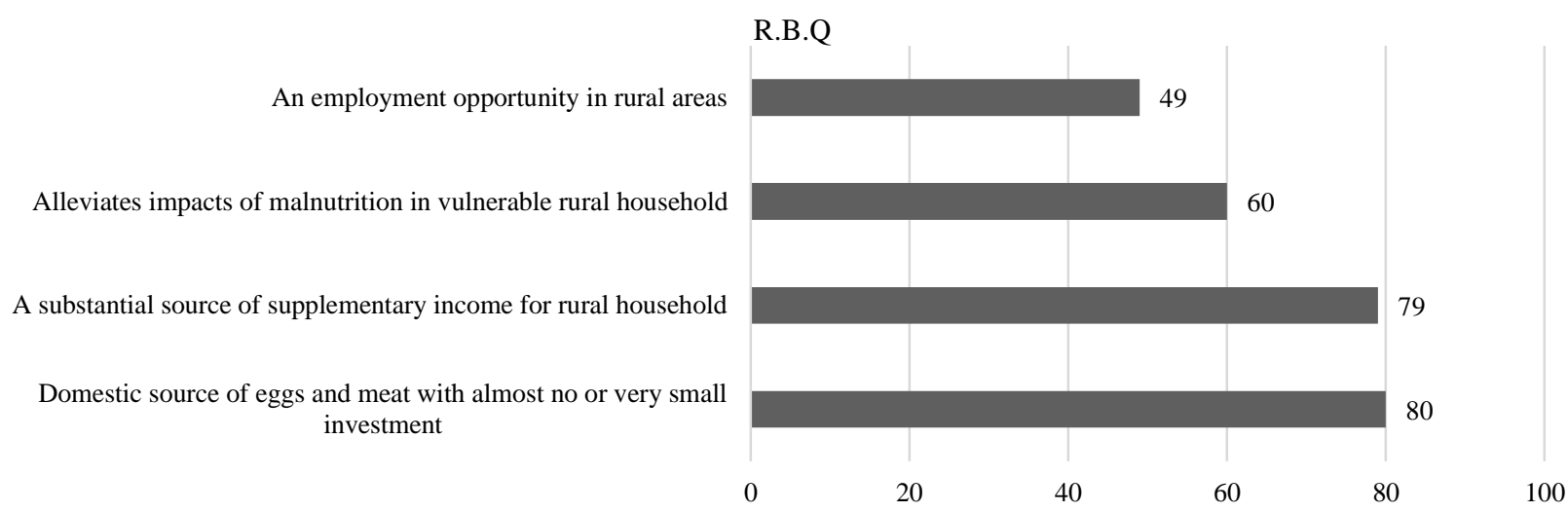

Figure 1b. Observed benefits of backyard poultry farming according to estimated R.B.Q in District Quetta

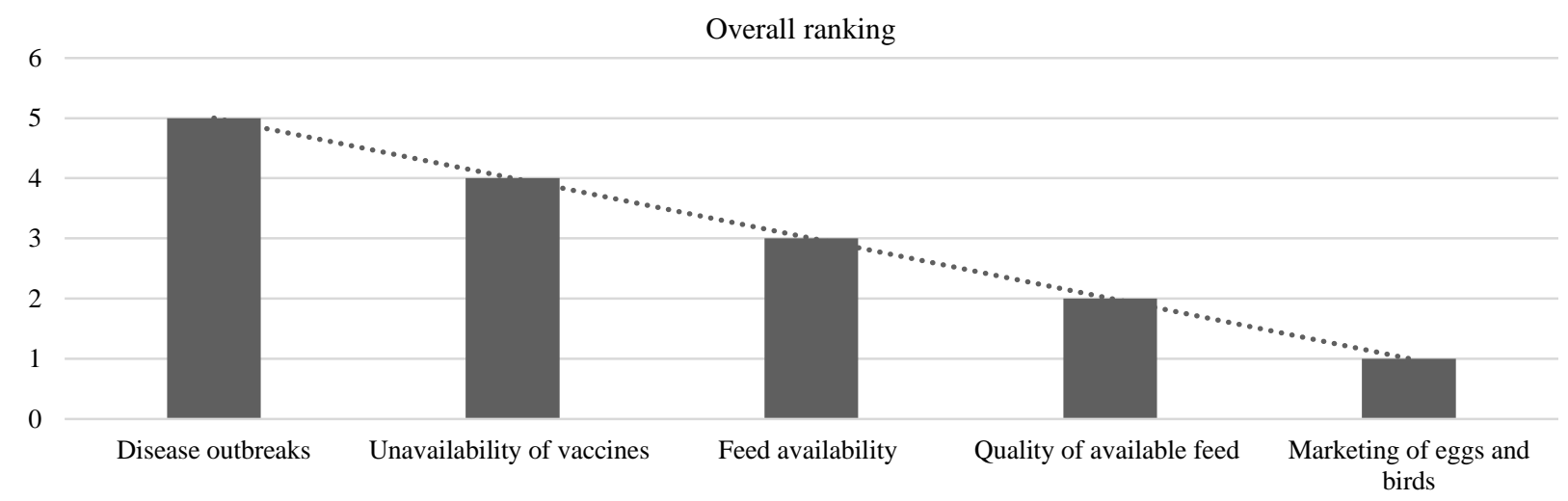

Figure 2a. Observed problems faced by respondents of backyard poultry farming according to their ranking in District Quetta 


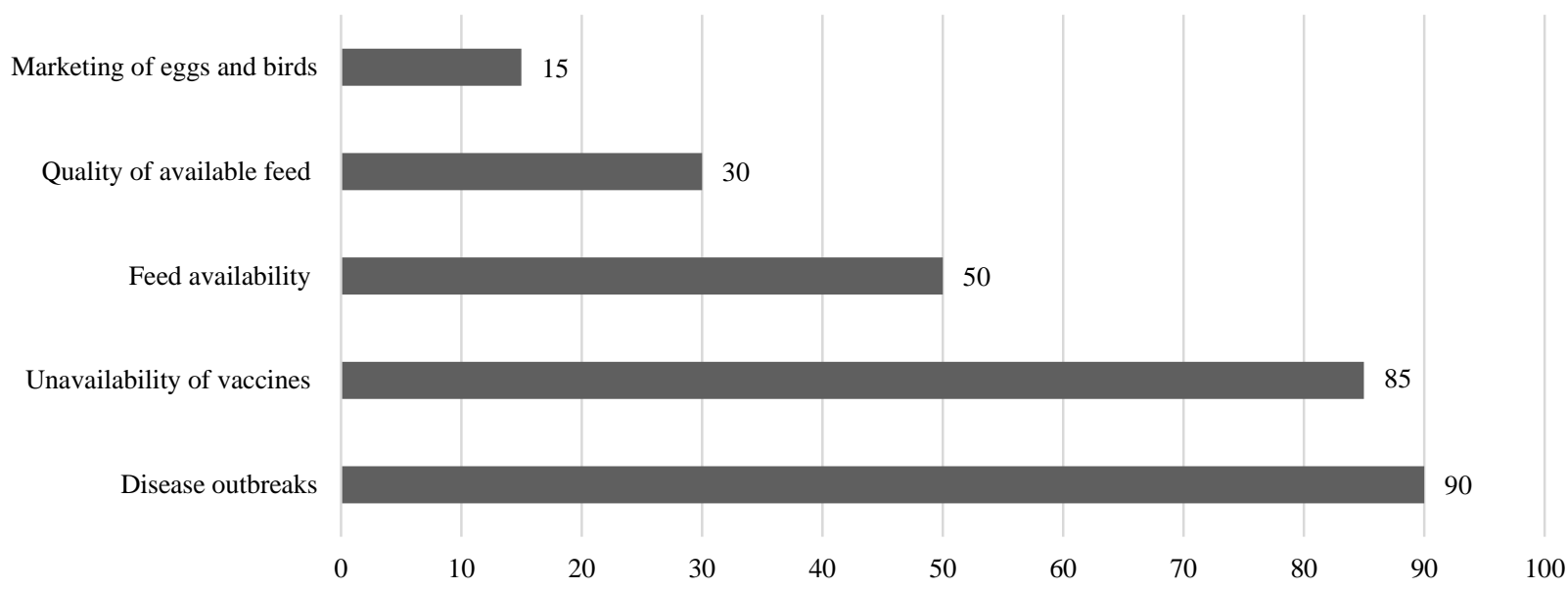

Figure $2 \mathrm{~b}$. Observed problems faced by respondents of backyard poultry farming according to estimated R.B.Q in District Quetta

\section{Conclusion}

It is concluded from the present study that backyard poultry farming is an important household enterprise in rural areas of district Quetta. It has an effective role in poverty alleviation both in terms of nutrition and as a source of supplementary income. Consequently, its importance in strengthening the livelihoods of farmers with limited living resources and landless dwellers in rural areas cannot be neglected. It is however, emphasized that problems and needs of these rural farmers must be identified and prioritized by involving the relevant farmers (Mathialagan and Sabarathinam, 2013). The solutions of these problems and related technological needs must then be ranked in a scientific way. This might help to adopt effective strategies to develop viable technologies and implementation of successful extension programs, which would ultimately boost backyard poultry production and will consequently improve the role of this enterprise in poverty alleviation and economic uplift of these farmers.

\section{References}

Ahuja V. 2004. Livestock and Livelihoods: Challenges and opportunities for Asia in the emerging market environment, national dairy development board of India and food and agriculture. (Ed. Ahuja V.), Organization of the United Nations. 372 p.

Alabi RA, Esobhawan AO, Aruna MB. 2006. Econometric determination of contribution of family poultry to women's income in Niger Delta, Nigeria. J. of Central European Agri, 7(2): 753-760.

Ahuja V, Sen A. 2007. Viability and future of small scale commercial poultry production in developing countries. Paper presented at Int. Conference on Poultry in the $21^{\text {st }}$ Century: Avian Influenza and Beyond, Bangkok, Nov. 5-7, 2007.

Ahuja V, Dhawan M, Punjabi M, Maarse L. 2008. Poultry based livelihoods of rural poor: Case of Kuroiler in West Bengal. National Dairy Development Board of India and Food and Agri. Organization of the United Nations, $57 \mathrm{p}$.

Awasthi PK, Tomar A, Raghuwanshi NK. 2015. Poverty reduction through strengthening backyard poultry farming in central India: An economic analysis. Int. J. Food Agri. Vet. Sci., 5(1): 11-17.
BRSP. 2018. (Balochistan Rural Support Programme), Livelihood sector in Balochistan. https://www.brsp.org.pk /sector/livelihood. Accessed on October 20.

Dolberg F. 2004. Review of Household Poultry Production as a Tool in Poverty Reduction with Focus on Bangladesh and India. (Ed.Ahuje,V.) Livestock and Livelihoods: Challenges and Opportunities for Asia in the Emerging Market Environment, National Dairy Development Board, India and Pro-Poor Livestock Policy Facility (South Asia Hub) of FAO. Pp. 68.

Debnath MK, Majumder D, Das PK. 2011. Status of backyard and small scale poultry production to sustainable livelihoodA case study. J. Crop and Weed, 7(2): 113-115.

Dhaka BL, Meena GS, Bairwa RK, Meena NL. (2017). Supplementing Rural Livelihoods through Backyard Poultry Farming. Int. J. Curr. Microbiol. App. Sci. 6(4): 1412-1415. DOI: https://doi.org/10.20546/ijcmas.2017.604.172

Islam R, Kalita N, Nath P. 2014. Comparative performance of Vanaraja and Indigenous chicken under backyard system of rearing. J. Poultry Sci. Technol., 2(1): 22-25.

Larbi MB, Hamdi NM, Haddad B. 2013. Indigenous chicken production systems in villages in the south of Tunisia. Livestock research for rural development. 25(6).

Meena KC, Singh B. Shivhare MK. 2012. Nutritional and livelihood security through backyard poultry for small and landless labours. Current Opinion in Agri., 1(1): 24-26.

Mathialagan P, Sabarathinam VE. 2013. An efficient methodology to identify technological needs and problems of poultry farmers. Inter J. Agri. Biosci, 2(6): 365-370.

Obi TU, Olubukola OA, Maina GA. 2008. Pro-poor HPAI risk reduction strategies in Nigeria: Background Paper. DFID Propoor HPAI Risk Reduction Strategies Project, Africa / Indonesia Region Report No. 5.

Pervaiz S. 2011. District Quetta Development Profile. Planning \& Development Department Balochistan Quetta. Pp. 131.

Pathak PK, Nath BG. 2013. Rural poultry farming with improved breed of backyard chicken. J. World's Poult. Res., 3(1): 2427.

Patel SK, Machhar RG, Kacha HL, Rani RR, Patel GD, Patel UM. 2014. Effect of backyard poultry farming on living standard of tribal farmers in Dahod district of Gujarat, India. J. Poultry Sci. Technol., 2(4): 79-83.

Pradeepta KR, Prasanna KM, Bandi KM, Nrusingha CB. 2015. Evaluation of different age quality traits and interpretation of their mode of inheritance in white leghorns. Veterin. World, 8: 449-452. DOI: 10.14202/vetworld.2015.449-452 
Rath PK, Mandal KD, Panda P. 2015. Backyard Poultry Farming in India: A Call for Skill Up-liftment. Review Paper. Res. J. of Recent Sci. 4(IVC-2015): 1-5.

Sabarathnam VE, Vennila S. 1996. Estimation of Technological Needs and Identification of Problems of Farmers for Formulation of Research and Extension Programmes in Agricultural Entomology. J. of Exp. Agric., 32 (1): 87-90. DOI: $10.1017 /$ S0014479700025898.

Sarwar F, Usman M, Umar S, Hassan M, Rehman A, Rashid A. 201). Some aspects of backyard poultry management practices in rural areas of district Rawalpindi, Pakistan. Int. J. of Livestock Res. 5(5): 14-20. DOI 10.5455/ijlr.20150215090127
Sonaiya EB. 2007. Family Poultry, food security and the impact of HPAI. World's Poultry Sci. J., 63 (1): 132-138.

Smucker, TA, Wisner B. 2008. Changing household responses to drought in Tharaka, Kenya: vulnerability, persistence and challenge. Disasters, 32(2): 190-215.

Uzunlu V, Bayaner A, Beniwal SPS. 1999. Problem identification and priority setting in agricultural research: the case of the eastern margin of Central Anatolia. Tr. J. of Agric. and Forestry; 23: 679-686.

WORLDATLAS. 2019. https://www.worldatlas.com/as/pk/ba/ where-is-quetta.html (Accessed: 10/07/2019) 